\title{
PENGGUNAAN METODE FINITE DIFFERENCE TIME DOMAIN (FDTD) DALAM SIMULASI PHASED ARRAY ANTENNA
}

\author{
Hadi Teguh Yudistira ${ }^{1}$, Hermawan K. Dipojono ${ }^{2,3}$, Andriyan Bayu Suksmono ${ }^{4}$ \\ ${ }^{1}$ Program Studi Teknik Mesin, Institut Teknologi Sumatera, Lampung, Indonesia \\ ${ }^{2}$ Kelompok Keahlian Teknik Fisika, Institut Teknologi Bandung, Bandung, Indonesia \\ ${ }^{3}$ Pusat Penelitian Nanosains dan Nanoteknologi Institut Teknologi Bandung, Bandung, Indonesia \\ ${ }^{4}$ Sekolah Teknik Elektro dan Informatika, Institut Teknologi Bandung, Bandung, Indonesia
}

\begin{abstract}
:
Finite Diffrence Time Domain is a simulation method which is used in the simulation of electromagnetic waves that uses the basic principle of numerical approach of differential equations in the domain of space and time. Phased array antenna is one type of antenna that can be applied to automotive radar. The simulated phased array antenna consists of microstrip antenna with the number of 64 antennas (8 rows, 8 columns). Microstrip antenna consists of 3 parts of patch, substrate and ground. The patch size on the microstrip antenna is $1.2 \times 2.6 \mathrm{~mm}$. The relative permittivity of substrate was used is 10.2. The simulation result is the radiation pattern of phased array antenna in form of directional.
\end{abstract}

Keyword: Finite Difference time domain, electromagnetic wave, Maxwell equation, phased array antenna, micristrip antenna, patch

\section{Pendahuluan}

Gelombang elektromagnetik merupakan salah satu gelombang yang digunakan dalam kehidupan sehari-hari. Salah satu aplikasi dari gelombang elektromagnetik adalah antena. Telepon genggam merupakan salah satu teknologi yang menggunakan antena. Phased Array Antenna (PAA) merupakan salah satu jenis antena yang dapat dikembangkan menjadi automotive radar. Antena merupakan suatu sistem pemancaran dan penerima yang dirancang untuk memancarkan atau menerima gelombang elektromagnetik [1]. Simulasi merupakan metode yang digunakan untuk memahami suatu fenomena fisis dalam tingkat perancangan. Dalam perancangan suatu teknologi aplikasi gelombang elektromagnetik diperlukan simulasi pola radiasi gelombang elektromagnetik. Dasar dari gelombang elektromagnetik adalah persamaan Maxwell. Oleh karena itu, simulasi gelombang elektromagnetik pada dasarnya adalah menyelesaikan persamaan Maxwell.

FDTD (Finite Difference Time Domain) merupakan metode numerik diferensial yang sering digunakan dalam simulasi gelombang elektromagnetik. Metode FDTD menggunakan pendekatan diferensial dalam domain ruang secara eksplisit dan menggunakan pendekatan diferensial dalam domain waktu secara implisit. Pertama kali diperkenalkan oleh Yee, metode FDTD telah digunakan dalam berbagai masalah $[2,3]$. Algoritma yang digunakan cukup sederhana dalam pendekatan secara numerik dari bentuk diferensial persamaan Maxwell. Yee menggunakan kisi medan listrik (E) dan medan magnet $(\mathrm{H})$ berselang dalam ruang dan waktu agar komputasi dapat dilakukan dengan menghitung persamaan medan sebagai fungsi medan sebelumnya. Dasar dari algoritma Yee adalah aproksimasi dengan ekspansi Taylor orde dua dalam ruang dan waktu. Dispersi numerik dan kesalahan akibat kisi yang tidak beraturan dapat diminimalkan dengan memberikan jumlah kisi ruang persatuan panjang gelombang yang sesuai [3].

\subsection{Persamaan Maxwell}

\section{Teori Dasar}

Fenomena listrik dan magnet dalam tingkat makroskopik dapat dimodelkan melalui persamaan Maxwell yang ditemukan oleh Maxwell pada tahun 1873. Persamaan Maxwell ini merupakan hasil simpulan dari ilmu pengetahuan elektromagnetik pada saat masa tersebut dan hipotesa dari teori pergerakan arus listrik yang ditemukan oleh Hertz dan Marconi. Maxwell memanfaatkan dasar empirik dan teori yang dikembangkan oleh Gauss, Ampere, Faraday dan ilmuwan yang lainnya [4]. Secara umum persamaan Maxwell yang tergantung terhadap waktu adalah sebagai berikut: 


$$
\begin{gathered}
\nabla \times \boldsymbol{E}=-\frac{\partial \boldsymbol{B}}{\partial t} \\
\nabla \times \boldsymbol{H}=\boldsymbol{J}+\frac{\partial \boldsymbol{D}}{\partial t} \\
\nabla \cdot \boldsymbol{D}=\rho \\
\nabla \cdot \boldsymbol{B}=0
\end{gathered}
$$

dimana persamaan (1) adalah hukum induksi Faraday, (2) merupakan hukum Ampere, dan (3) serta (4) adalah hukum Gauss masing-masing untuk medan listrik dan magnet. Ketika $\boldsymbol{J}$ bernilai nol maka persamaan Maxwell akan menjadi persamaan Maxwell untuk keadaan tanpa sumber [3].

Pada ruang bebas sumber, hubungan antara medan listrik dan medan magnet dengan fluks medan listrik dan fluks medan magnet adalah sebagai berikut:

$$
\begin{aligned}
& \mathrm{B}=\mu_{o} \mathrm{H} \\
& \mathrm{D}=\varepsilon^{\varepsilon_{o}} \mathrm{E}
\end{aligned}
$$

dimana permeabilitas udara $\mu_{o}=4 \pi \times 10^{-7}$ Henry $/ \mathrm{m}$ dan permitivitas udara ${ }^{\varepsilon_{o}}=8.854 \times 10^{-12}$ farad $/ \mathrm{m}$ $[4,5]$.

\subsection{Penurunan Algoritma FDTD}

Dari persamaan 1 dan persamaan 2 dapat diketahui bahwa $\mathbf{E}$ dan $\mathbf{H}$ merupakan besaran vektor pada ruang tiga dimensi. Misalkan diambil satu dimensi yaitu hanya $E_{x}$ dan $H_{y}$ jadi persamaan 1 dan persamaan 2 menjadi

$$
\begin{gathered}
\frac{\partial \boldsymbol{E}}{\partial t}=\frac{1}{\varepsilon_{0}} \nabla \times \boldsymbol{H} \rightarrow \frac{\partial E_{x}}{\partial t}=-\frac{1}{\varepsilon_{0}} \frac{\partial H_{y}}{\partial z} \\
\frac{\partial \boldsymbol{H}}{\partial t}=\frac{1}{\mu_{0}} \nabla \times \boldsymbol{E} \rightarrow \frac{\partial H_{y}}{\partial t}=-\frac{1}{\mu_{0}} \frac{\partial E_{x}}{\partial z}
\end{gathered}
$$

Dari persamaan 7 dan persamaan 8 dapat diketahui bahwa medan listrik memiliki harga pada sumbu $\mathrm{x}$, medan magnet memiliki harga pada sumbu y. Medan listrik dan medan magnet akan memiliki arah propagasi ke arah sumbu $z$.

Persamaan 7 dan persamaan 8 dapat diubah dalam bentuk pendekatan diferensial secara numerik sehingga diperoleh:

$$
\begin{aligned}
& \frac{E_{x}^{n+1 / 2}(k)-E_{x}^{n-1 / 2}(k)}{\Delta t}=-\frac{1}{\varepsilon_{0}} \frac{H_{y}^{n}(k+1 / 2)-H_{y}^{n}(k-1 / 2)}{\Delta z} \\
& \frac{H_{y}^{n+1}(k+1 / 2)-H_{y}^{n}(k+1 / 2)}{\Delta t}=-\frac{1}{\mu_{0}} \frac{E_{x}^{n+1 / 2}(k+1)-E_{x}^{n+1 / 2}(k)}{\Delta z}
\end{aligned}
$$

Pada persaman 9 dan persamaan 10, peubah n menyatakan peubah jumlah waktu (time step). Untuk menentukan waktu sebenarnya adalah dengan cara mengalikan jumlah waktu dengan perbedaan waktu. Gambar 1 merupakan gambar penjelasan mengenai algoritma FDTD untuk domain waktu dan domain ruang. 


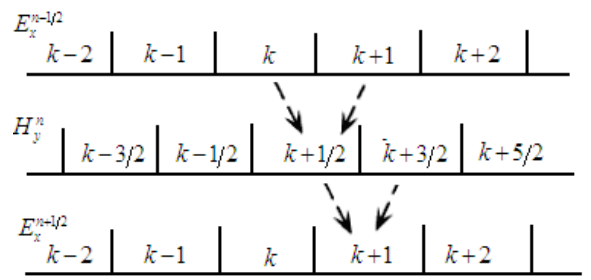

Gambar 1 Kisi FDTD Yee terhadap ruang dan waktu [3]

Dari Gambar 1 dapat dilihat bahwa untuk mencari besar $\mathrm{H}_{\mathrm{y}}$ pada waktu sekarang dibutuhkan besar dari $E_{x}$ yang terletak pada kisi di sebelahnya dan pada waktu sebelumnya. Begitu juga untuk mencari besar $\mathrm{E}_{\mathrm{x}}$ pada waktu sekarang dibutuhkan besar dari $\mathrm{H}_{\mathrm{y}}$ yang terletak pada kisi di sebelahnya dan pada waktu sebelumnya. Perhitungan yang dideskripsikan pada Gambar 1 berlaku untuk semua domain ruang. Di sini akan digunakan unit (Gaussian) normalisasi pada persamaan diferensial Maxwell dengan mensubstitusikan

$$
\text { E? } \sqrt{\frac{\varepsilon_{0}}{\mu_{0}}} \boldsymbol{E}
$$

yang digunakan untuk menyederhanakan formula FDTD [6]. Persamaan 11 disubstitusikan ke persamaan 9 dan persamaan 10 maka diperoleh nilai baru masing-masing komponen medan sebagai berikut:

$$
\begin{aligned}
& \operatorname{tg}_{x}^{1 / 2}(k)=E_{x}^{n} \text { 图 }(k)-\frac{1}{\sqrt{\varepsilon_{0} \mu_{0}}} \frac{\Delta t}{\Delta z}\left[H_{y}^{n}(k+1 / 2)-H_{y}^{n}(k-1 / 2)\right] \\
& H_{y}^{n+1}(k+1 / 2)=H_{y}^{n}(k+1 / 2)-\frac{1}{\sqrt{\varepsilon_{0} \mu_{0}}} \frac{\Delta t}{\Delta z}\left[{\frac{H^{-}}{x}}^{1 / 2}(k+1)-E_{x}^{n} \text { 圆 }(k)\right] \\
& \Delta t=\frac{\Delta x}{2 c_{0}} \\
& \frac{1}{\sqrt{\varepsilon_{0} \mu_{0}}} \frac{\Delta t}{\Delta x}=c_{0} \frac{(\Delta x / 2) c_{0}}{\Delta x}=\frac{1}{2}
\end{aligned}
$$

\subsection{Microstrip Antenna (MA)}

MA mendapat perhatian pada tahun 1970-an, walaupun ide dari MA muncul pada tahun 1953 dan menjadi paten pada tahun 1955. MA terdiri dari logam yang sangat tipis dan bahan substrat. Susunan dari MA adalah sebagai berikut: bidang dasar (ground), bahan substrat, dan logam tipis (patch). Gambar 2 merupakan gambar MA.

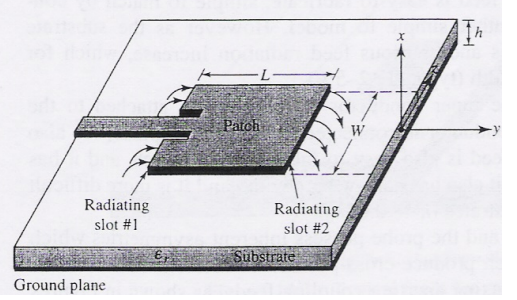

Gambar 2 Gambar Microstrip Antenna [7] 
Dari Gambar 2 terlihat bahwa patch terletak pada bagian atas bahan substrat yang memiliki ketebalan h. Bagian bawah dari MA adalah bidang dasar yang memiliki sifat seperti bahan konduktor sebagaimana halnya patch. Besar permitivitas relatif bahan substrat yang digunakan untuk MA berada di daerah 2.2 sampai 12 [7]. Patch memiliki beberapa bentuk, yaitu persegi, persegi panjang, lingkaran, elips, segitiga dan berbagai bentuk yang lain.

\subsection{PHASED ARRAY ANTENNA (PAA)}

PAA merupakan antena yang dapat memancarkan dan juga menerima radiasi gelombang elektromagnetik dari sudut arah yang cukup luas tanpa menggerakkan antenanya. Untuk pemancaran gelombang elektromagnetik biasanya dikendalikan oleh penggeser fasa [8]. Gambar 3 merupakan sketsa dari PAA dengan menggunakan penggeser fasa dan rangkaian distribusi arus.

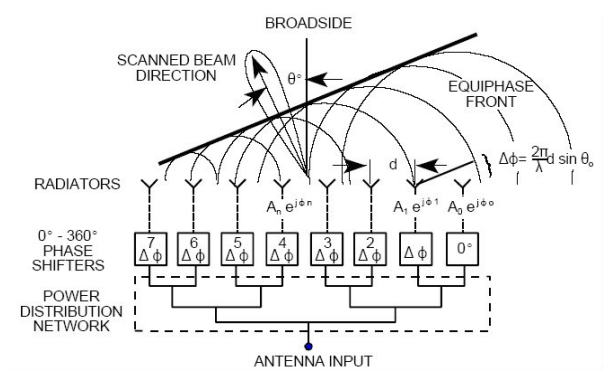

Gambar 3 Sketsa Phased Array Antenna [8]

Dari Gambar 3 dapat dilihat bahwa pada titik tertentu PAA akan memancarkan radiasi gelombang elektromagnetik pada sudut tertentu. Gelombang elektromagnetik akan dipancarkan pada berbagai sudut dikarenakan adanya susunan beberapa antena dengan pola tertentu pada PAA.

\section{Simulasi}

\subsection{Pemodelan Antena}

Antena yang akan disimulasikan merupakan PAA. Setiap elemen array pada PAA merupakan MA dengan patch berbentuk persegi panjang. Gambar 4 merupakan sketsa PAA yang disimulasikan dalam tugas akhir ini.

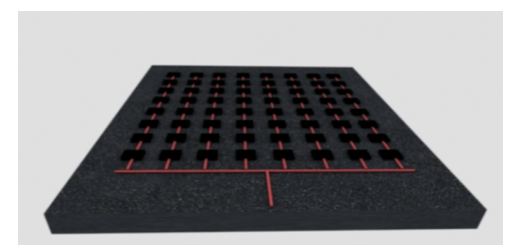

Gambar 4 Sketsa Phased Array Antenna

Dari Gambar 4 dapat dilihat bahwa pada permukaan bahan substrat terdapat 64 elemen patch $(8 \times 8$ elemen). Patch terbuat dari logam yang memiliki sifat seperti konduktor. Di antara patch dengan bidang dasar terdapat substrat yang terbuat dari bahan dielektrik. Permitivitas relatif bahan dielektrik yang digunakan adalah 10,2. Bidang dasar terletak pada lapisan terbawah.

Patch yang digunakan berbentuk persegi panjang dengan ukuran $1.2 \times 2.6 \mathrm{~mm}$. Tebal dari patch adalah $0.2 \mathrm{~mm}$.

\subsection{Pemodelan Sumber}

Sumber yang digunakan adalah Ultra Wide Band (UWB) pulse excitation merupakan sinyal pulsa Gausian dikalikan dengan sinyal sinusoida [9]. Script sinyal pulsa Gausian adalah sebagai berikut:

$\mathrm{dz}($ is $, \mathrm{jlo}, 1: \mathrm{kt})=\mathrm{J0} 0^{*}(\mathrm{n}-\mathrm{ndelay})^{*} \exp \left(-\left((\mathrm{n}-\mathrm{ndelay})^{\wedge} 2 / \mathrm{tau}^{\wedge} 2\right)\right)$;

script sinyal pulsa Gausian ini digunakan oleh Keely J. Willis dari University of Wisconsin-Madison pada penelitiannya.

Script untuk sinyal UWB pulse excitation adalah sebagai berikut:

$\mathrm{dz}($ is $, \mathrm{jlo}, 1: \mathrm{kt})=\mathrm{J} 0^{*}(\mathrm{n}-\mathrm{ndelay})^{*} \exp \left(-\left((\mathrm{n}-\mathrm{ndelay})^{\wedge} 2 / \mathrm{tau}^{\wedge} 2\right)\right){ }^{*} \sin \left(2^{*} \mathrm{pi}^{*} \mathrm{fc}^{*}(\mathrm{n}-\mathrm{ndelay})\right) ;$. 
Gambar 5 merupakan gambar grafik sinyal UWB pulse excitation antara amplituda dengan jumlah waktu.

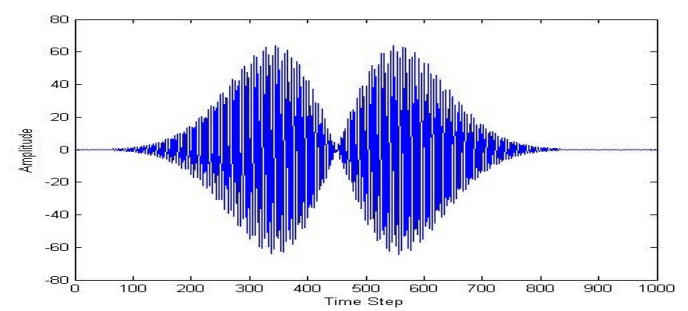

Gambar 5 Grafik Sinyal UWB Pulse Excitation

Dari Gambar 5 dapat dilihat bahwa sumber yang diberikan memiliki amplituda yang besar adalah di antara jumlah waktu ke 100 sampai jumlah waktu ke 800. Sehingga daerah pengamatan radiasi gelombang elektromagnetik yang efektif terletak di daerah jumlah waktu ke 100 sampai jumlah waktu ke 800 .

\subsection{Hasil Simulasi}

Gambar 6 merupakan gambar yang menjelaskan daerah pengamatan radiasi medan listrik.

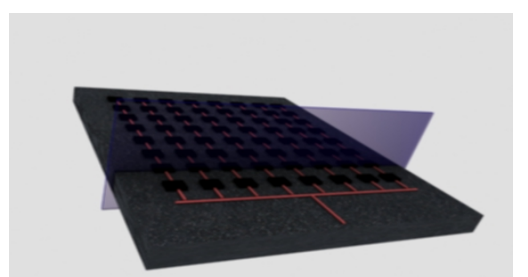

Gambar 6 Visualisasi Daerah Pengamatan pada j=25

Pada Gambar 6 terdapat bidang yang membelah bagian phased array antenna. Bidang ini merupakan bidang pengamatan radiasi medan listrik. Hasil pola radiasi yang diperoleh dengan daerah pengamatan yang sesuai dengan Gambar 6 adalah Gambar 7.

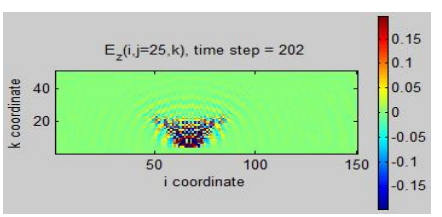

(a) Jumlah waktu 202

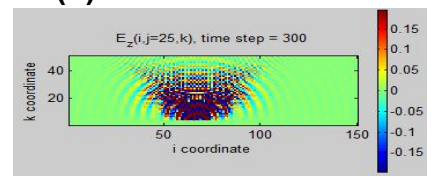

(b) Jumlah waktu 300

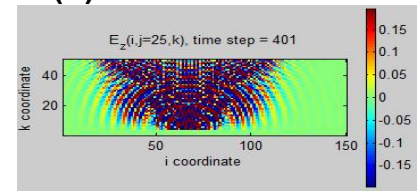

(c) Jumlah waktu 401

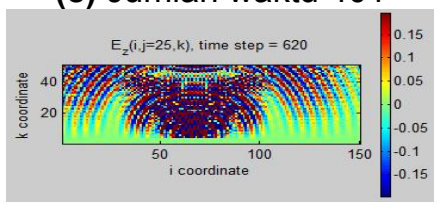

(d) Jumlah waktu 620

Gambar 7 Radiasi Medan Listrik Komponen z pada j=25 
Gambar 7 merupakan gambar radiasi medan listrik komponen z pada j=25. Dari Gambar 7 dapat dilihat bahwa pada saat jumlah waktu 202 memiliki radiasi medan listrik komponen $z$ lebih kecil dibandingkan pada saat jumlah waktu 300, 401 dan 620. Hal ini dikarenakan pada saat jumlah waktu 202 sumber pada antenna memancarkan medan listrik lebih kecil dibandingkan pada jumlah waktu 300, 401 dan 620. Dari Gambar 7 dapat dilihat bahwa radiasi medan listrik komponen z membentuk sudut terhadap normal bidang. Pada Gambar 7.c dan Gambar 7.d terlihat bahwa radiasi dari medan listrik tidak seperti pada Gambar 7.a dan Gambar 7.b yang beam medan listrik masih terlihat jelas. Hal ini dikarenakan adanya propagasi medan listrik dari beam.

\section{Kesimpulan}

Dari hasil simulasi yang diperoleh dapat disimpulkan bahwa:

1. Pola radiasi yang dipancarkan oleh PAA adalah directional dengan sudut tertentu terhadap normal bidang

2. Jika medan yang dihasilkan besar maka medan tersebut dengan mudah meradiasi ke lingkungan sekitar beam utama.

3. Medan listrik pada komponen $z$ memiliki nilai medan terbesar dibandingkan dengan komponen y dan komponen $\mathrm{x}$. Hal ini dikarenakan sumber yang diberikan hanya pada komponen $\mathrm{z}$.

4. Medan listrik pada komponen $x$ memiliki beam utama hasil radiasi lebih rapi dibandingkan dengan medan listrik komponen yang lain. Hal ini dikarenakan medan listrik pada komponen $x$ memiliki nilai medan yang terendah.

\section{Penghargaan}

Hadi Teguh Yudistira (Penulis) mengucapkan terima kasih kepada program studi Teknik Fisika ITB dikarenakan hasil ini merupakan hasil penelitian penulisa ketika menumpuh pendidikan sarjana di Teknik Fisika ITB. Penulis juga mengucapkan terima kasih kepada Prof. Ir. Hermawan K. Dipojono, MSEE, Ph.D dan Prof. Andriyan Bayu Suksmono, Ph.D sebagai pembimbing penulis selama mengerjakan penelitian ini.

\section{Daftar Pustaka}

[1] A. Taflove, Computational Electrodynamics: The Finite-Difference Time-Domain Method, Boston: Artech House, 1995, pp. 477.

[2] Gregory M. Turner, and Christos Christodoulou, "FDTD Analysis of Phased Array Antennas" IEEE Transactions on Antennas and Propagation, vol. 47, No. 4, April 1999.

[3] Musa, "Perfectly Matched Layer Pada Elektromagnetik," Tugas Akhir S1 Teknik Fisika, Institut Teknologi.

[4] D.M. Pozar, Microwave Engineering Third Edition, New York: John Wiley \& Sons, Inc, 2005, pp. 5-6.

[5] W. H. Hayt,Jr, Elektromagnetika Teknologi, Jakarta: Penerbit Erlangga, 1989, pp. 111-123.

[6] D.M. Sullivan, Electromagnetic Simulation Using The FDTD Method, IEEE Press, 2000.

[7] C. A. Balanis, Antenna Theory Analysis and Design, New York: John Wiley \& Sons, Inc, 1997, pp. 723-730.

[8] R.C Johnson and H. Jasik, Antenna Engineering Handbook second Edition, New York: Mc Graw Hill, 1984, Chapter 20.

[9] R.W. Brocato, "FDTD Simulation Tools for UWB Antenna Analysis", Sandia National Laboratories, California, 2004. 